\title{
Bottom-Up Approach for Cartography Body of Knowledge Design
}

\author{
Vit Vozenilek ${ }^{\mathrm{a},}$, , Vaclav Talhofer ${ }^{\mathrm{b}}$ \\ ${ }^{a}$ Palacky University Olomouc, Czech Republic, vit.vozenilek@upol.cz \\ ${ }^{b}$ University of Defence, Czech Republic, vaclav.talhofer@unob.cz \\ * Corresponding author
}

Keywords: Body of Knowledge, Curriculum, Bottom-Up Approach, Cartography

\begin{abstract}
:
Body of Knowledge (BoK) is a term used to represent the complete set of concepts, terms and activities that make up a professional domain, as defined by the relevant professional association. Body of Knowledge is a set of professional competencies that must be available (understood thoroughly and used correctly) by each of the clearly defined professions. While the term body of knowledge is also used to describe the document that defines that knowledge - the body of knowledge itself is more than simply a collection of terms, a professional reading list, a library, a website or a collection of websites, a description of professional functions, or even a collection of information. It is the accepted ontology for a specific domain (https://www.definitions.net/).
\end{abstract}

After analysing strategic document on body of knowledge designing, implementation and usage, the authors outline the bottom-up approach for body of knowledge design intended for cartography (CartoBoK) within their long-term experience in academic positions.

The objective of CartoBoK is to define the basis for the completing of curricula for programs under accreditation and courses of cartography. Another objective of CartoBoK is a contribution to the completing of teaching materials. The purpose of CartoBoK is to be generally accepted material in the compilation, approval and control of accreditations, testing, admission procedures, the building of NQF (National Qualifications Framework), etc. The CartoBoK describes and structures the knowledge areas needed to define a curriculum in cartography. It is not about creation an allencompassing extensive document with strict requirements for higher education in cartography. It is about focusing on defining key topics for the preparing university graduates with appropriate education in cartography. CartoBoK:

- $\quad$ will enable future employers of graduates to study cartography, resp. parts of cartography, and to place graduates in appropriate job positions;

- will contribute to the development of cartography, especially in education, in keeping with world trends;

- will include the required knowledge of graduates in future job positions within governmental authorities and organizations, commercial entities, non-profit organizations and various levels of the education system.

CartoBoK as a system consists of three components of cartographic topics (elements) and their relations (links), competencies and professions. The components follow current frameworks of the authors' cartography study curricula that they introduced at their universities. The construction of CartoBoK from topics through competencies to professions is an effort to apply the approach of designing CartoBoK from the bottom to up and at the same time to project in it two existing successful curricula for cartography in the Czech Republic.

Topics are the main knowledge areas of cartography forming roots for higher levels. They include knowledge areas that should not directly match a particular course in a curriculum. They distinguish between three types of topics: core topics that should be mandatory for each curriculum, dilative topics that are expected to be covered at 90-100\%, and elective topics. The bottom-up approach suggests that the cartography curriculum should include all core topics and all or almost the dilative topics. Core and dilative topics are defined differently for different university programmes and specialisations. To be complete a curriculum should cover in addition to the core and dilative topics significant amount of elective topics. The reason for such a hierarchical bottom-up approach to the structure of the CartoBoK is a useful way to group related information, not as a structure for organizing material into courses only.

Competencies are key abilities of graduates forming the knowledge-skill base for cartography at a higher level. The CartoBoK considers multidisciplinarity of current cartography through spatial competencies and technical competencies including practical skills. While the technical competencies are specific to IT skills and specify a set of demonstrable abilities of graduates to perform some specific functions. The so-called work-place skills describe the ability the graduates to operate effectively as a member of a diverse team, to read and interpret technical information, to engage in continuous 
learning, to have professional, legal, and ethical behaviour, and to demonstrate business awareness and workplace effectiveness.

Professions are job positions in cartographic disciplines developing the graduate for a specific focus. There are three main "cartographic professions" as target groups for CartoBoK:

- a professional cartographer - PROCART - a graduate is employed as a cartographer, i.e. cartographic activity dominates in the description of his job position in state administration (mapping agency, ministry of defence), state authorities and other ministries (transportation, interior, agriculture, environment, foreign affairs, etc.), commercial sector (cartographic publishing houses, online service providers,...), non-profit organizations; the content of his workload is classified as topographic cartographer, geographical cartographer or thematic cartographer;

- $\quad$ an expert-noncartographer - NOCART - a graduate is employed as a university/research expert in various professions, i.e. in the description of his job position and the content of his workload; a geographer, a geologist a demographer, an architect are examples of mentioned professions; maps (making and use) has an important role;

- a geography teacher - TEAGEO - the graduate is employed at primary or secondary school as a geography teacher and, among other things, teaches mainly tasks with maps and partly the basics of map making; it should be considered to distinguish between teacher for primary and secondary schools and for universities with a pedagogical focus or a scientific focus.

The topics of knowledge areas have to be required in all cartographic professions, but they differ in the depth of it (Figure 1).

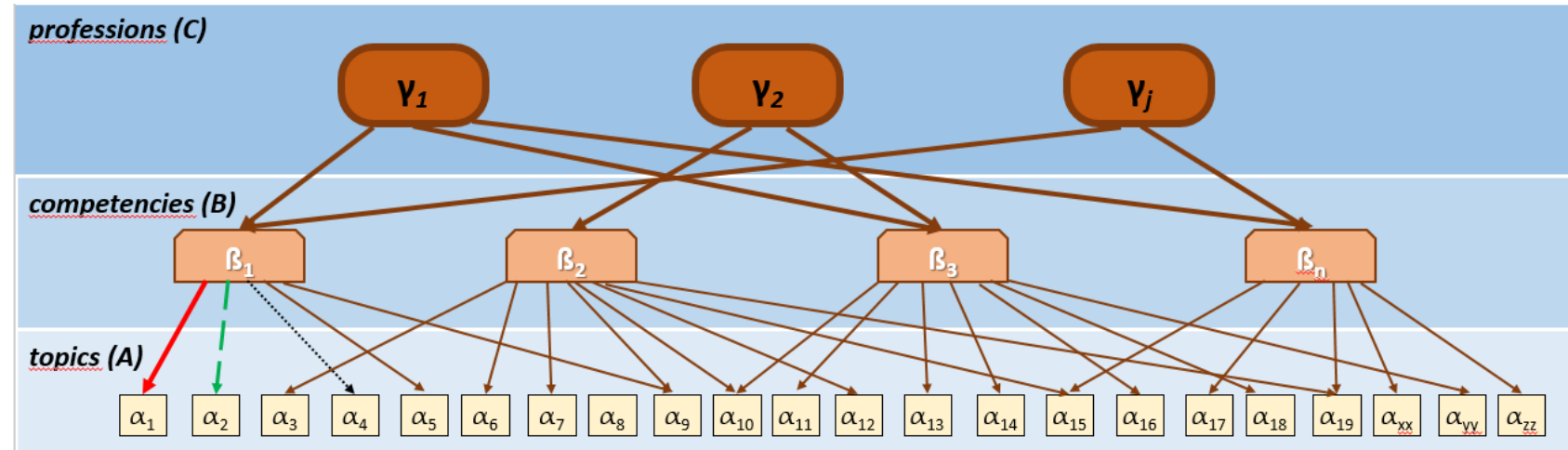

Topics in knowledge areas are asquired in scope:

practice - can use correctly

- theory - knows their definition, classification, derivation, etc.

- awareness - has sufficient subconsciousness to be able to explain and defend their role and necessity.

Figure 1. CartoBoK in a hierarchical structure for bottom-up approach.

Cartography Body of Knowledge (CartoBoK) is designed in hierarchical structure consisting of three levels:

- lower (university) level - each university defines its own (university) body of knowledge by approving the curricula of its study program; there are hundreds of university BoK that vary according to university capacities or societal requirements;

- intermediate (national) level - if national authority implements a legislative framework regulating the content of syllabi of study programs with national validity, we can speak of a national BoK;

- $\quad$ upper (international) level - ICA can offer the final concept of BoK lower levels.

The bottom-up approach was considered as the main concept for the CartoBoK design and follows four steps:

(i) reviewing of theoretical BoK issues and examples of existing BoKs for cartography worldwide,

(ii) considering of the current development of CartoBoK in ICA,

(iii) defining a structure of the Czech CartoBoK (CartoBoK-Cze),

(iv) loading the CartoBoK-Cze.

Recently the authors have elaborated the joint CartoBoK of their two universities curricula, and will invite other universities to implement their cartographic curricula to the national CartoBoK-Cze. 